Eur 7 Cancer, Vol. 29A, No. 16, pp. 2335-2336, 1993 Printed in Great Britain $0959-8049 / 93 \$ 6.00+0.00$

(C) 1993 Pergamon Press Ltd

\section{Urinary System Tumours in a Familly}

\section{Valgardur Egillsson, Gudmundur Vikar Einarsson, Pall Thorhallsson and Sigurdur Ingvarsson}

FAMILIAL CLUSTERING of upper urothelial tumours is uncommon. Radovanic et al. [1] have reported four siblings (of five), diagnosed at the age of 62-88 years, with malignant upper urothelial tumours (UUT) in a family living in Serbia. Balkan nephropathy (BN), a disease endemic in certain districts of the Balkan countries, is associated with a high frequency of UUT. Patients with cancer of the renal pelvis often develop tumours in the urinary bladder and even at the ureteric orifice; the latter have been suggested to derive from cells secondarily implanted [2]. Hereditary factors have been suggested in the aetiology of bladder cancer [3]. Renal pelvis cancer and ureteric cancer are rare, while cancer in the urinary bladder is common, and more common in Iceland than in other Scandinavian countries, as is renal cell carcinoma [4].

We report here a family in which nine primary tumours were diagnosed altogether in four members (mother and three of her offspring) (Fig. 1, and case notes below). Five of the nine tumours were urothelial in origin and the sixth was renal cell carcinoma (clear cell type). The three other cancers were in the colon, thyroid gland and breast. The family lived on a farm. The affected mother was born 1874. Her children, born between 1906 and 1917, were brought up on the family farm, but later moved to surrounding villages or to the town of Reykjavik. None of the three affected siblings had offspring.

Correspondence to S. Ingvarsson.

S. Ingvarsson, V. Egilsson and P. Thorhallsson are at the Department of Pathology; and G.V. Einarsson is at the Department of Surgery, National University Hospital Box 1465, IS-121 Reykjavik, Iceland.

Revised 26 Oct. 1992; accepted 25 Nov. 1992.
Case IV8, the affected mother, had urinary bladder cancer (two separate tumours) of transitional papilliferous type, age 76 (non-smoker).

Case V12 had pulmonary tuberculosis at the age of $\sim 25$ years, was otherwise in good health and was a smoker. Renal pelvic carcinoma (right) was found age 78, transitional papilliferous type and urinary bladder carcinoma transitional papilliferous type, age 81. Autopsy showed metastatic growth in lungs, haemangioma of liver, as well as stenosis of the other ureter with severe hydronephrosis and atrophy of the renal parenchyme; also, hyperplastic nodule in the thyroid gland.

Case V15 had pulmonary tuberculosis age 23 but was otherwise in good health until the age of 70 (non-smoker). Renal pelvic carcinoma (right), transitional papilliferous type and ureter carcinoma (right, lower third), transitional cell type were then seen. Ureter cancer in situ was seen in the upper middle section of the right ureter. Autopsy showed thyroid carcinoma with regional lymph node metastases, papilliferous type and widespread abdominal metastases of the urothelial cancer type. The other ureter showed stenosis with hydronephrosis.

Case V18 had myomata uteri, hysterectomy and ovariectomy (age 46). Renal carcinoma (right), clear cell type were diagnosed at age 67. Also, breast cancer (right), age 67, ductal invasive adenocarcinoma, negative for oestrogen and progesterone receptors. Colon cancer, left flexure, adenocarcinoma, was discovered at autopsy as well as widespread metastases of renal cell type and haemangioma in the liver.

Individual IV9 (the husband of the affected mother) stems from a family in which no cancer is known in 1st or 2nd degree relatives. Two brothers of the mother were free of cancer, as well as their offspring, nine altogether (branch B). Malignancies appeared in more distant relatives (branch C), e.g. renal and breast carcinoma in a sibling group, whether relevant or not.

From information gathered we cannot suggest any particular environmental factors to explain such a clustering of urothelial tumours in two generations, as seen in this family. No stomach cancer has been observed, although it was very common in Iceland earlier this century [5]. No endemic nephropathy is known in the country.

The affected mother's parents were blood-related, which suggests the involvement of a hereditary factor. The possibility

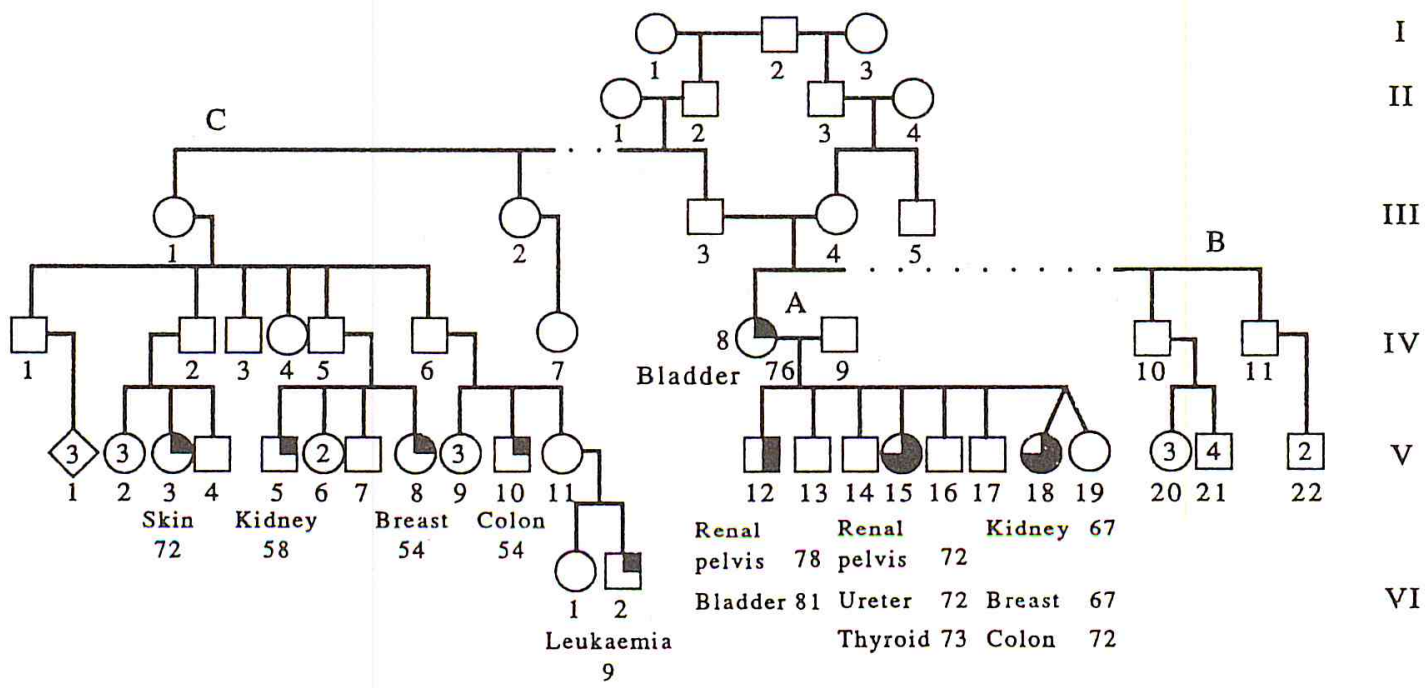

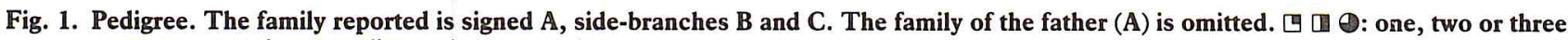
primary malignancies, respectively. Organ involved and age at diagnosis is marked at the pedigree. 
of the hereditary susceptibility is supported by the finding of multiple primaries in three of eight offspring of the affected mother, while branch B is free of the malignancies. The occurrence of malignancies in the three other organs will be left undiscussed for the time being. We will, however, mention 1 female patient in our clientele belonging to a breast cancer family. This woman had breast cancer at the age of 61 , renal cell carcinoma (clear cell type) age 67 as well as transitional cell cancer of the lower ureter discovered at the same age.

High incidence of colorectal cancer and urinary tract tumours, including renal cell carcinoma has been reported in families [6]. Urothelial tumours are also recognised as part of the Lynch II cancer family syndrome [7].

With this report we add evidence to the growing body of information suggesting a hereditary factor in the aetiology of urothelial tumours. Clustering of four members from the same nuclear family is unlikely to be caused by environmental factors alone.

1. Radovanovic Z, Velimirovic D, Naumovic T. Upper urothelial tumours and the Balkan nephropathy, inference from the study of a family pedigree. Eurf Cancer 1990, 26, 391-392.

2. Sidransky D, Frost P, Von-Eschenbach A, Oyasu R, Preisinger AC, Vogelstein B. Clonal origin bladder cancer. N Engl f Med 1992, 326, 737-740.

3. Kramer AA, Graham S, Burnett WS, Nasca P. Familial aggregation of bladder cancer stratified by smoking status. Epidemiology 1991, 2, 145-148.

4. Perry SB, Thorhallsson P, Hallgrimsson J. Tumours in Iceland. Acta Path Microbiol Immunol Scand Sect A 1982, 90, 175-183.

5. Sigurjónsson J. Geographical variations in mortality from cancer in Iceland with particular reference to stomach cancer. $\mathcal{F}$ Natl Cancer Inst 1966, 37, 337-346.

6. Budd DC, Fink LC. Mucoid colonic carcinoma as an autosomaldominant inherited syndrome. Arch Surg 1981, 116, 901-905.

7. Meclin JP, Jarvinen HJ. Tumor spectrum in cancer family syndrome (hereditary nonpolyposis colorectal cancer). Cancer 1991, 68, 1109-1112.

Acknowledgements-The authors wish to thank the Icelandic Cancer Society, the Science Fund of Iceland, the Memorial Fund of Bergthora Magnusdottir and Jakob B. Bjarnason and the University Research Fund for financial support. 